\title{
Verticillium Wilt Evaluation of Olive Breeding Selections Under Semi-Controlled Conditions
}

\author{
A. Serrano, ${ }^{\dagger}$ D. Rodríguez-Jurado, B. Román, J. Bejarano-Alcázar, R. De la Rosa, and L. León \\ The Andalusian Institute of Agriculture and Fishery Research and Training (IFAPA), Alameda del Obispo, Avenida Menéndez \\ Pidal, Córdoba, Spain
}

\begin{abstract}
Genetic resistance is the most recommended measure to control verticillium wilt in olive (VWO), a vascular disease caused by the soil-borne fungus Verticillium dahliae, which has promoted the development of olive breeding programs aimed at obtaining new resistant and highly yielding cultivars in recent years. Screening has been commonly performed under controlled conditions in grow chamber after artificial inoculation during the early stage of breeding programs, but additional evaluation is necessary to confirm previous results as well as to test for additional agronomic traits. During this study, 20 breeding selections initially classified as resistant to the disease have been re-evaluated in artificially infested soils under natural environmental conditions. The maximum disease incidence $(52.6 \%)$ was reached at 26 months after planting, and the disease intensity index reached the maximum value of $38.5 \%$ at 29 months after planting. Nine breeding selections consistently

confirmed the previous results regarding resistance to $V$. dahliae infection; however, contradictory results, compared with those of previous evaluations under controlled conditions in grow chambers, were obtained for the rest of selections tested, thereby underlining the need for long-term experimentation under natural environmental conditions. Additional positive agronomic traits, such as early bearing, were also observed for some of the resistant selections, but plant vigor varied. Some seem highly promising for release as new cultivars when characterization of other important agronomic traits is completed in the future.

Keywords: defoliating pathotype, environmental conditions, genetic resistance, Olea europaea L., plant-pathogen interaction, screening, Verticillium dahliae Kleb.
\end{abstract}

Olive (Olea europaea subsp. europaea var. europaea L.) is one of the oldest fruit trees traditionally cultivated throughout the Mediterranean basin. Olive growing has been continuously expanding, both in traditional and nontraditional cultivation areas, and boosted by technological improvements in the irrigation, mechanization, and higher planting density of growing systems (Fernández-Escobar et al. 2013).

During the expanding process, new olive groves have been planted in areas traditionally cultivated with different crops, consequently resulting in new challenges derived from these new conditions. Therefore, in some areas, olive orchards were established in soils infested by Verticillium dahliae, which is a soil-borne fungus causing wilting diseases in many crops and the causal agent of Verticillium Wilt in olive (VWO) (Jiménez-Díaz et al. 2011; López-Escudero and Mercado-Blanco 2011; Navas-Cortés et al. 2008). This pathogen is a major limitation for olive productivity in some new producing areas (Montes-Osuna and Mercado-Blanco 2020). Disease incidence and symptom severity mainly depend on the virulence of the $V$. dahliae pathotype, whereas inoculum density in soil was not directly related to the disease parameters in both natural infested fields and artificially infested microplots (López-Escudero and Blanco-López 2007; Roca et al. 2016). In this sense, the defoliating pathotype has been described as more virulent than nondefoliating (LópezEscudero et al. 2004) and the cause of most of the infections in Andalusian olive orchards (López-Escudero et al. 2010).

The use of cultivars resistant to VWO is the most recommended prevention measure to be considered before planting in potentially infested soils. Nevertheless, most of the evaluated traditional cultivars were susceptible, at least to the defoliating (D) $V$. dahliae

${ }^{\dagger}$ Corresponding author: A. Serrano;

alicia.serrano.gomez@juntadeandalucia.es

The author(s) declare no conflict of interest.

Accepted for publication 8 November 2020

(C) 2021 The American Phytopathological Society pathotypes, after many evaluation processes under different conditions in growth chambers (López-Escudero et al. 2004, 2007; Martos-Moreno et al. 2006), greenhouses (García-Ruiz et al. 2014, 2015), and fields (Trapero et al. 2013a) despite differences linked to the inoculation process (Cirulli et al. 2008; Trapero et al. 2013b). In all cases, widely variable disease development was observed among cultivars, ranging from highly resistant to extremely susceptible (López-Escudero et al. 2004). However, some of the cultivars identified as resistant in these works have exhibited negative agronomic traits that could limit their commercial use. These include late bearing, excessive vigor, frost susceptibility, and low oil content. Additionally, some experiments revealed that VWO imposes a limitation to plant growth (Birem et al. 2016; Sanei and Razavi 2017; Santos-Rufo et al. 2017) and yield (Gómez-Gálvez et al. 2020; Levin et al. 2003), and even affects oil quality (Landa et al. 2019). Even so, the negative impact of VWO shows variability among cultivars, with lower effects on resistant ones, which are recommended as a genitor in future breeding programs.

Therefore, because there is evidence of genetic variability in the VWO response of traditional cultivars, some breeding programs involving crosses between resistant genitors to obtain new cultivars combining both high resistance to VWO and improved agronomical traits were initiated (Arias-Calderón et al. 2014; Trapero et al. 2015). Different evaluation procedures have been tested for screening purposes; however, an evaluation step of resistance under natural environmental conditions is recommended before finally selecting new resistant genotypes. This is necessary to determine variability in the effects of natural environment conditions on the olive genotype reaction to $V$. dahliae. Under field conditions, the disease is subjected to several factors of the natural environment, including virulence variations and prevailing pathotypes, as well as the distribution of fungus inoculum in the soil. The D pathotype causes higher rates of disease incidence and more severe epidemics than the ND pathotype (López-Escudero and Blanco-López 2007; Navas-Cortés et al. 2008). The number of patches in the field could affect the disease incidence and severity, as has been found in other perennial hosts (Goud et al. 2011). Differences in optimum soil temperatures have been reported for specific pathotype infections (Calderón et al. 2014). Temperatures are also involved in the seasonal cycle of 
symptom expression (Levin et al. 2003; Trapero et al. 2013a) and could contribute to the natural recovery of symptoms in different cultivars (López-Escudero and Blanco-López 2005).

This work aimed to evaluate the VWO resistance of olive breeding selections under natural environmental conditions during a long-term experiment performed in microplots infested with a known defoliating isolate of $V$. dahliae. Disease response as well as other important agronomic traits such as plant growth and earliness of bearing were evaluated to select the most promising selections that could be recommended for olive growing in areas infested with $V$. dahliae.

\section{Materials and Methods}

Plant material. One-year-old plants of 20 breeding selections were obtained by vegetative propagation of semi-hardwood stem cutting (self-rooted plants). These selections were obtained during the olive breeding program of Andalusian Institute of Agriculture and Fishery Research and Training (IFAPA) from open pollination of different cultivars (Arbequina, Empeltre, Frantoio, Koroneiki, Picual, Picudo, and Manzanilla de Sevilla) or direct crosses (Changlot Real $\times$ Dolce Agogia, Frantoio $\times$ Arbosana, Frantoio $\times$ Dolce Agogia, Koroneiki $\times$ Empeltre). They were selected from the initial progenies based on their early crop (short juvenile period), high oil content (Arias-Calderón et al. 2014), and high level of resistance to $V$. dahliae when tested by root-dip inoculation under controlled conditions in a grow chamber (Arias-Calderón et al. 2015a, b). Plants of four cultivars were also included in the experiment as controls: Changlot Real and Frantoio as resistant; Picual as susceptible; and Arbequina, for which a variable disease response has been described depending on the evaluation conditions, i.e., susceptible in grow chamber experiments but resistant in field conditions (Trapero et al. 2013a).

Inoculum production and soil infestation. A monoconidial isolate of $V$. dahliae defoliating pathotype (Rodríguez-Jurado et al. 2008) belonging to the culture collection of the Sustainable Crop Protection Area of IFAPA Alameda del Obispo (Córdoba, Spain) was used in this experiment. The inoculum multiplication was performed in 1-liter Erlenmeyer flasks containing $0.5 \mathrm{~kg}$ of a cornmeal-sand substrate consisting of a sterilized mixture of sand, cornmeal, and distilled water in a weight proportion of 9:1:2, respectively. Then, each flask was inoculated by adding 25 disks with a 5 -mm diameter extracted from PDA ( $250 \mathrm{~g}$ peeled potato, $20 \mathrm{~g}$ agar, and $20 \mathrm{~g}$ glucose per liter) plates with pathogen mycelia and incubated for 8 weeks at $24 \pm 1^{\circ} \mathrm{C}$ in the dark, as previously described (Santos-Rufo et al. 2017). Flasks with PDA disks without fungus were included.

The experiment was conducted on 6- $\times 6$-m experimental microplots delimited by a 2-mm-thick high-density polyethylene sheet located in an open field $\left(37^{\circ} 51^{\prime} 23.8^{\prime \prime} \mathrm{N}, 4^{\circ} 48^{\prime} 02.7^{\prime \prime} \mathrm{W}\right)$ at the experimental field of IFAPA Alameda del Obispo, Córdoba, Spain. A total of 40 microplots were used; 20 were infested with the prepared inoculum and the other 20 were used as controls in an inoculum-free soil. The 20 microplots of each treatment (infested/non infested) were divided into 10 elementary plots of two microplots each. In each elementary plot, one tree of each of the 24 genotypes tested ( 20 breeding selections and 4 control cultivars) was randomly planted. Therefore, 12 trees were planted in each microplot. Infested microplots were separated from control microplots by a perimeter mesh to avoid contamination.

The microplots were infested 1 month before the planting date in March 2016. The inoculation consisted of spreading $7.5 \mathrm{~kg}$ of the fungal substrate on each microplot. This was homogeneously distributed in the microplot using a motor hoe digging $15 \mathrm{~cm}$ into the soil. The same procedure was applied for the control microplots but a noninfested substrate was used. The soil in microplots was characterized by a loam texture (clay $19.5 \%$, sand $41.5 \%$, and silt $39.0 \%$ ) and basic $\mathrm{pH}(8.45)$ with $1.11 \%$ of organic matter.

Assessment of plant growth, pathogen evolution, and environment conditions. Trunk diameters of $50 \mathrm{~cm}$ were measured after planting and annually to evaluate plant growth. In addition, the number of bearing trees was recorded in November 2017 and 2018.

The $V$. dahliae inoculum density was estimated at $0,3,7,12,19$, 24, and 31 months after planting using the wet sieving technique (Huisman and Ashworth 1974). For each sampling date, six subsamples of $200 \mathrm{~g}$ were collected in each microplot with an Edelman sampler at a depth of 0 to $15 \mathrm{~cm}$ between the tree rows. The six soil subsamples were mixed to make a single sample per microplot, processed by hand-crumbling, and left to air-dry for 4 weeks at room conditions. Afterward, each sample was sieved to remove organic debris and particles larger than $0.8 \mathrm{~mm}$. Duplicate samples containing $25 \mathrm{~g}$ of sieved soil from each microplot were suspended in $100 \mathrm{ml}$ of sterile distilled water, shaken for $15 \mathrm{~min}$ at $250 \mathrm{rpm}$, and filtered through nested $250-\mu \mathrm{m}$ and $20-\mu \mathrm{m}$ sieves to retain most of the persistent propagules of $V$. dahliae (Gómez-Gálvez et al. 2019). The soil residues retained in the $20-\mu \mathrm{m}$ sieve were recovered in $100 \mathrm{ml}$ of agar solution ( $1 \mathrm{~g}$ of agar diluted on 1 liter of sterile distilled water). Subsequently, $1-$ $\mathrm{ml}$ aliquots were plated onto sodium polypectate agar medium (Butterfield and DeVay 1977) using 10 plates for each replicate of $25 \mathrm{~g}$ of the soil sample. Plates were incubated for 14 days at $24 \pm 2{ }^{\circ} \mathrm{C}$ in the dark. After incubation, the soil particles on the plate surface was washed with tap water and $V$. dahliae colonies were counted under a stereoscopic microscope. The number of colonies was expressed as propagules per gram of air-dried soil (ppg) because each colony originated from a single propagule of the fungus.

The microplot soil temperature was registered hourly during 1 year of the total experiment period by probes and data loggers located in four different infested microplots at a depth of $15 \mathrm{~cm}$. Air temperatures were recorded by the meteorological station of the IFAPA Alameda del Obispo (Córdoba, Spain) located near the experimental trial area.

Disease assessment. Olive trees were visually evaluated every month for 33 months from March 2016 until December 2018. Symptom severity was assessed based on the percentage of the aerial part affected according to a scale from 0 to $4(0=$ healthy tree; $1=1 \%$ to $33 \%$ symptomatic; $2=34 \%$ to $66 \%$ symptomatic; $3=67 \%$ to $100 \%$ symptomatic; 4 = completely dead) (Rodríguez-Jurado 1993). During the evaluation period, the olive trees showing symptoms such as green defoliating or wilting leaves, chlorosis, curling leaves, and/or necrosis of shoots or branches were analyzed to confirm infection by $V$. dahliae. For this assay, two stems were sampled from the symptomatic branches, washed in running tap water, and disinfected in $10 \%$ sodium hypochlorite for $1 \mathrm{~min}$. Then, 3- to 5-mm stem pieces were plated on chlortetracycline water agar medium and incubated at $24^{\circ} \mathrm{C}$ in the dark. Approximately 9 days after plates were observed under a microscope to identify $V$. dahliae conidiophores and/or microsclerotia.

The disease incidence (DI) was calculated as the percentage of symptomatic olive trees. Disease severity scores were used to calculate several disease parameters comprising the relative susceptibility index (RSI), which was calculated according to Arias-Calderón et al. (2015b).

$$
\begin{aligned}
R S I & =[0.3 \times R A U D P C+0.2 \times F D I I+0.3 \times F D P I+0.05 \times F D I \\
& +0.15 \times(100-R D P F)] \times \frac{100}{S P}
\end{aligned}
$$

where the relative area under the disease progress curve (RAUDPC) was calculated according to the following formula:

$$
R A U D P C=\frac{100}{\left(s_{\max } \times t_{T}\right)} \times \sum_{i=1}^{n} \frac{\left(s_{i}+s_{i+1}\right)}{2} \times \Delta t
$$

For RAUDPC: $\mathrm{s}_{\max }$ is the maximum value of severity (4); $\mathrm{t}_{\mathrm{T}}$ is the total evaluation period ( 33 months); $s_{i}$ is the severity value of the experimental unit in observation $\mathrm{i} ; \mathrm{n}$ is the number of observations; and $\Delta \mathrm{t}$ is the time between observations.

The disease intensity index (DII) was calculated for each observation time using the following formula:

$$
D I=\sum_{x=1}^{n} \frac{\left(s_{x} \times n_{x}\right)}{\left(4 \times n_{T}\right)} \times 100
$$

In which $s_{x}$ is the disease severity value for individual olive trees; $\mathrm{n}_{\mathrm{x}}$ is the number of olive trees with the $\mathrm{s}_{\mathrm{x}}$ value; and $\mathrm{n}_{\mathrm{T}}$ is the total number of olive trees for the experimental unit.

The final disease incidence (FDI), final disease intensity index (FDII) and final dead plant incidence (FDPI) were estimated as the values for those parameters. The relative disease-free period (RDFP) corresponds to 
the percentage of time before the appearance of symptoms with reference to the total experiment period. The SP represented the average of the susceptibility index obtained for the susceptible reference cultivar (Picual).

Olive tree recovery and death rates were also calculated as a percentage of the total symptomatic trees evaluated for each genotype. Recovery from disease was considered when an infected olive tree continued growing or resprouted with a diminishing percentage of the symptomatic aerial part until it completely overcame disease symptoms and reached a severity value of 0 .

Statistical analysis. Statistical analyses were performed using R version 3.6.2. Homogeneity of variances was tested using the Levene test of the car package. Disease parameters, for which the homogeneity of variances was not met, were analyzed by the KruskalWallis test using the agricolae package, followed by the post hoc Dunn's pairwise multiple comparison test of the dunn.test package. Spearman rank correlations were performed using the corrplot package to evaluate relationships between RAUDPC and RSI at different times to decide the optimum evaluation period. For all analyses, significant differences were considered when $P<0.05$.

\section{Results}

Verticillium wilt development. Visual symptoms of disease were not observed on any of the olive trees from the control noninfested microplots throughout the experimental period; however, for olive trees in infested microplots, disease symptoms were first observed 3 months after planting (MAP) (Fig. 1). Defoliation of green leaves was the most frequent symptom, although slow decline and apoplexy with leaf curling and wilting were observed in several cases, but it was not linked to any specific genotype or observation time. For all symptomatic cases, $V$. dahliae infection was confirmed by fungal isolation in the laboratory.

Symptoms increased irregularly in olive trees throughout the evaluation period. The first plant deaths were observed 3 months after planting and corresponded with the first plants showing symptoms. However, disease development was variable among trees. Sometimes $V$. dahliae infection was lethal to the olive tree; however, in other cases, symptoms affected only certain shoots or branches and other healthy branches continued growing. Remission of symptoms was observed in several affected olive trees; eventually, some of them were considered completely recovered from the disease symptoms.

The average DI increased steadily up to $26 \mathrm{MAP}$, during Spring 2018, when the percentage of total infected trees reached its maximum value of $52.9 \%$ (Fig. 1A). From that moment, an observed decline in the average DI value was associated with symptom recovery of some olive trees; this was more evident at the end of the
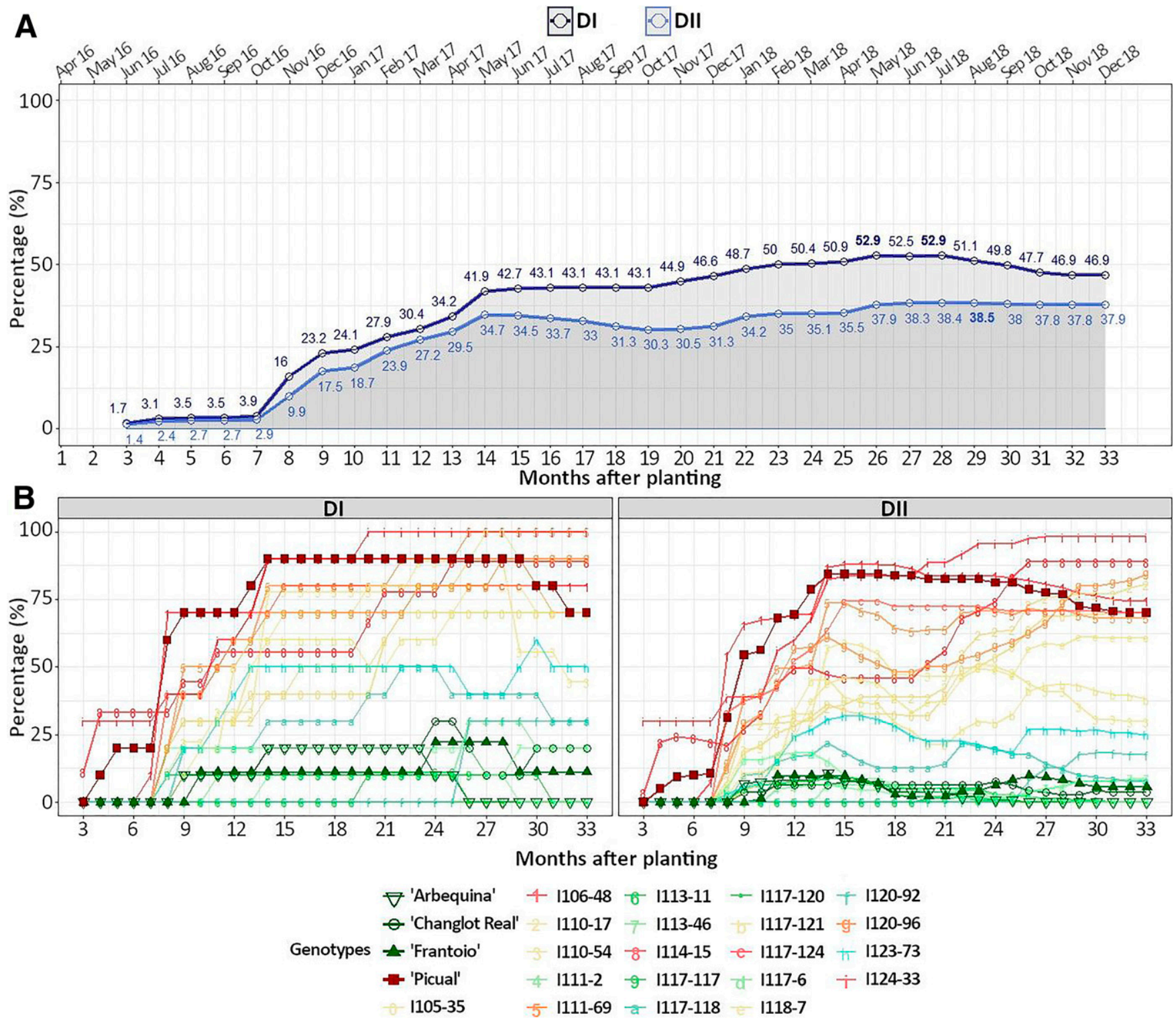

Fig. 1. Disease progression of 24 genotypes evaluated in Verticillium dahliae-infested microplots for 33 months. A, Average disease incidence (DI) and disease intensity index (DII) for all infested trees of the experiment. B, The DI and DII for individual genotypes. 
experiment. Recovered olive trees were observed for the four control cultivars (Picual, Arbequina, Changlot Real, and Frantoio) and 10 of the evaluated breeding selections (I106-48, I110-54, I111-2, I113-11, I117-117, I117-118, I117-121, I117-124, I117-6, and I123-73), as shown by the decrease in the individual DI values of those genotypes (Fig. 1B). It is worth noting that the susceptible control 'Picual' reached its maximum incidence at 14 MAP (May 2017), similar to I106-48, I117117, and I117-6, whereas the incidence continued increasing for the rest of the genotypes. The genotypes showing initial symptoms later were registered at $30 \mathrm{MAP}$ and corresponded to 'Changlot Real' and I123-73.

The DII curve first increased and then fluctuated until the end of the evaluation period (Fig. 1). Although the first symptoms were observed 3 MAP, it was not until the following autumn that the average DII started to increase significantly (from 7 MAP). At 1 year after planting and after spring (13 to $15 \mathrm{MAP}$ ), the average DII reached values of $34.5 \%$ to $34.75 \%$, which were quite close to the average

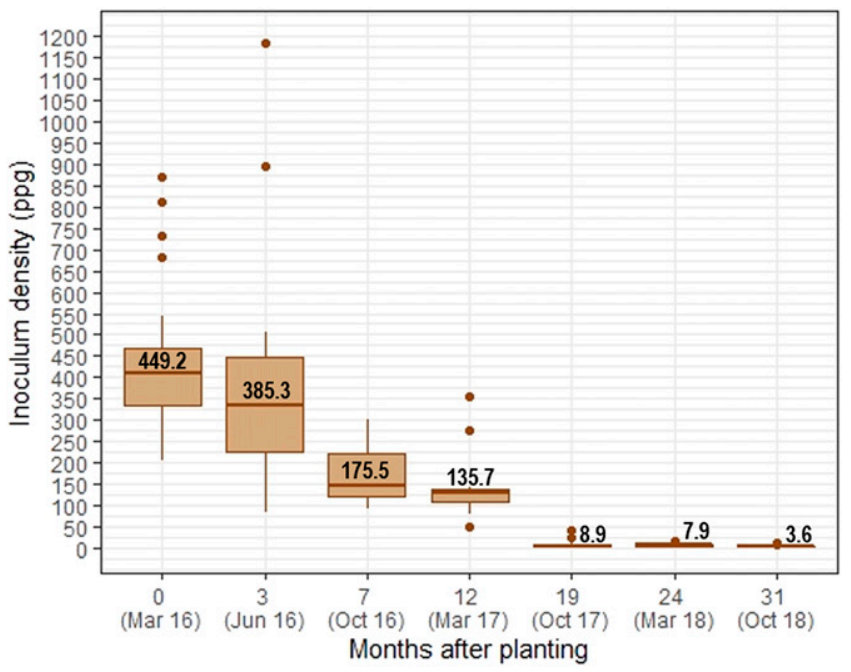

Fig. 2. Variation of the Verticillium dahliae inoculum density over time. value maximum (Fig. 1A). Remission of severe symptoms was observed during 16 to 19 MAP (summer and early fall), producing decreased average DII values. Then, the severity of symptoms increased again until 29 MAP, when the DII reached the maximum value of $38.5 \%$ (Fig. 1A) just after another disease outbreak during the second spring evaluation period (25 to 27 MAP). Declining DII values from 29 to 33 MAP were attributable to lower symptom severity and total recovery of some symptomatic olive trees, which also reduced the total DI values. However, several breeding selections, such as I105-35, I11017, I118-7, and I120-96, reached the maximum individual DII value during the last months (Fig. 1B). Fluctuations of the DII values for single genotypes across time were attributable to the onset and remission of symptoms in some olive trees, which eventually led to total or partial recovery or death of the tree.

A quarterly analysis of soil inoculum revealed that the fungus remained viable during the evaluation period. The mean inoculum density of the total treatment continuously decreased over time, from 449.2 ppg at planting to $385.3 \mathrm{ppg}$ at first symptoms (3 MAP) and $3.6 \mathrm{ppg}$ at 31 MAP, although wide variability was measured in the different microplots at each sampling time (Fig. 2).

Environment (air and soil) temperature, which is considered an important factor in disease progress and fungus survival, was monitored for 1 year, from December 2016 to December 2017, and corresponded to the period from 9 to 21 MAP (Fig. 3). The overall fluctuation in temperature was higher in air $\left(-3.4\right.$ to $\left.44.9^{\circ} \mathrm{C}\right)$ than in soil (5.1 to $35.8^{\circ} \mathrm{C}$ ). Intraday variability of temperatures was also higher in air than in soil because of the higher minimum and lower maximum temperatures in the soil. The average daily mean temperature in soil was generally slightly higher than the average daily air temperatures, ranging from 6.4 to $32.7^{\circ} \mathrm{C}$ in soil and from 4.1 to $33.1^{\circ} \mathrm{C}$ in air during the total registered period. During this monitored period, the peak of the disease incidence was observed at 14 MAP (corresponding to May 2017). A mean air temperature of $20.7^{\circ} \mathrm{C}$ and mean soil temperature of $24.4^{\circ} \mathrm{C}$ were registered at this time, with variations ranging from $6.6^{\circ} \mathrm{C}$ to $34.5^{\circ} \mathrm{C}$ and $16.1^{\circ} \mathrm{C}$ to $31.2^{\circ} \mathrm{C}$ in air and soil, respectively.

Classification of genotypes. Significant differences among genotypes were observed for all disease parameters and two categories were clearly obtained for all of them. None of the genotypes showed an intermediate disease response (Table 1). For RAUDPC, values

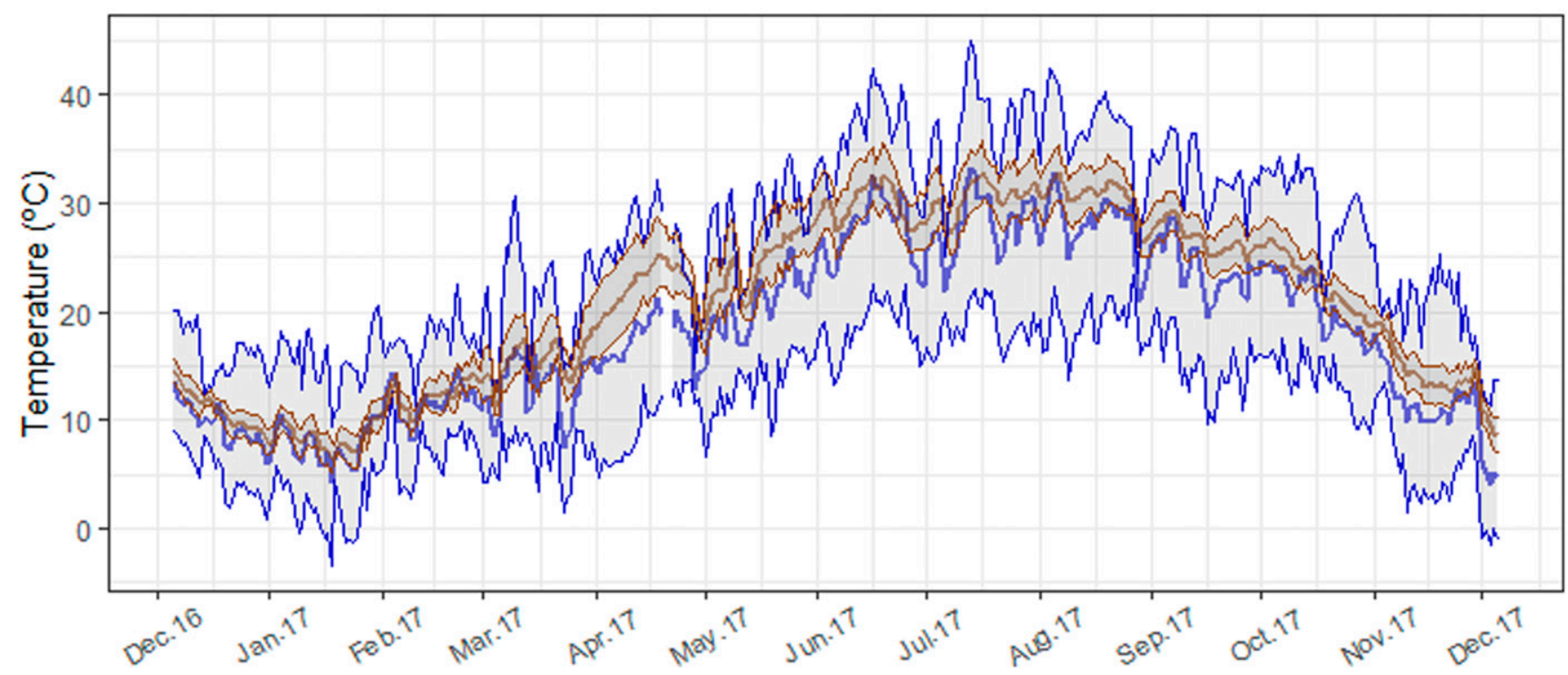

Fig. 3. Daily air and soil temperatures (average, maximum, and minimum) in the experimental field from December 2016 (9 months after planting [MAP]) to December 2017 (21 MAP). 
more than $24.3 \%$ corresponded to susceptible genotypes, whereas resistant genotypes showed values less than $17.7 \%$. It is noteworthy that I117-120 was the only genotype without symptomatic trees during the evaluation period. I113-11, I117-117, 'Arbequina', and I1176 also showed null FDII and FDI values, but disease symptoms were observed in some olive trees at some point during the experimental period; however, they totally recovered. However, $100 \%$ of olive trees belonging to I124-33 and I111-69 were symptomatic (FDI = $100)$ at the end of the assessment period.

In general, susceptible genotypes began to develop symptoms earlier than resistant ones; therefore, the resistant ones showed higher RDFP values (Table 1). Similarly, susceptible genotypes reached higher FDPI values, corresponding to higher death rates than those of the resistant ones (Fig. 4). Among resistant genotypes, only I123-73 showed FDPI values different from 0; additionally, this genotype displayed an FDI of $50 \%$, which was statistically different from that of 'Arbequina' (Table 1). Therefore, although it was categorized as resistant based on the RSI value, it could be reconsidered as susceptible because of the values of the other disease parameters. In this sense, 70\% of I123-73 trees showed symptoms at any time during the assessment period, although the registered recovery rate was $29 \%$ (Fig. 4). Similarly, some susceptible genotypes also had higher incidences than those shown at the end of the experiment (FDI), such as 'Picual', I117-124, I118-7, I110-54, and I117-121, which had a certain capacity to recover from disease symptoms. In contrast, $V$. dahliae infection was especially lethal for symptomatic trees of I1 14-15 and I105-35, for which the death rate reached $100 \%$ (Fig. 4). In general, susceptible genotypes had more severe symptoms and higher death rates, whereas resistant genotypes had mainly mild or moderate symptoms, high recovery rates, and null death rates.

The RSI was finally used to categorize the verticillium wilt response of the different genotypes into two groups, resistant and susceptible, to show the significant differences between them. As expected, disease parameters for the Picual cultivar showed susceptible response to $V$. dahliae. In contrast, 'Arbequina' revealed values for disease parameters that were similar to those of traditional resistant controls 'Changlot Real' and 'Frantoio'. A total of 11 of 20 breeding selections were susceptible; among these, I124-33, I114-15, and I106-48 exhibited higher RSI values than the susceptible reference 'Picual'. Similarly, three resistant selections (I117-120, I113-11, and I117-117) had lower RSI values than the best resistant control cultivar.

A comparison of the results obtained during this work with those previously obtained for the same genotypes under root-dip artificial inoculation and evaluation in a growth chamber showed low correlations for RAUDPC and RSI parameters at the end of the experimental period for both methodologies, with Spearman $r$ values of 0.37 and 0.4 , respectively (Fig. 5). However, a high correlation between RAUDPC and RSI was revealed for microplot results obtained during different timeframes. Correlation coefficients were high for evaluations performed from 9 to $33 \mathrm{MAP}$, with an $\mathrm{r}$ value close to 1 for those performed from 28 to 33 MAP.

Effect of Verticillium wilt on tree vigor and fruit bearing. Tree growth assessed through measurements of the trunk diameter was, in general, lower for infested than for noninfested plants (Fig. 6). The differences were more evident in trees expressing disease symptoms and more remarkable for susceptible genotypes, whereas low variability in trunk diameters was observed for resistant ones, particularly at the end of the experimental period. Frantoio was the most vigorous among resistant cultivars, and 'Picual' and I111-69 were the most vigorous among susceptible genotypes (Fig. 6). Resistant breeding selections showed wide variability in trunk diameter measurements; among them, similar trunk diameters were registered for I117-117, I113-11, I117-120, and 'Arbequina'.

Table 1. Disease parameters measured 33 months after planting and resistance classifications of the 24 genotypes evaluated (20 breeding selections and four control cultivars)

\begin{tabular}{|c|c|c|c|c|c|c|c|}
\hline \multirow[b]{2}{*}{ Genotype } & \multicolumn{6}{|c|}{ Disease parameters $^{\mathbf{a}}$} & \multirow[b]{2}{*}{ Resistance category ${ }^{b}$} \\
\hline & RAUDPC & FDII & FDI & RDFP & FDPI & RSI & \\
\hline I124-33 & $68.9 \mathrm{ACF}$ & $98.1 \mathrm{ACF}$ & $100.0 \mathrm{AF}$ & $30.3 \mathrm{ACF}$ & $90.0 \mathrm{ACF}$ & 125.1 ACF & S \\
\hline I114-15 & $50.6 \mathrm{ACF}$ & $88.9 \mathrm{ACF}$ & 88.9 ACF & $43.8 \mathrm{ACF}$ & $88.9 \mathrm{ACF}$ & 109.6 ACF & $\mathrm{S}$ \\
\hline I106-48 & $60.9 \mathrm{ACF}$ & $74.4 \mathrm{ACF}$ & $80.0 \mathrm{ACF}$ & $35.2 \mathrm{ACF}$ & $70.0 \mathrm{ACF}$ & $102.6 \mathrm{ACF}$ & S \\
\hline 'Picual' & $58.9 \mathrm{ACF}$ & $70.0 \mathrm{ACF}$ & $70.0 \mathrm{ACF}$ & $33.3 \mathrm{ACF}$ & $70.0 \mathrm{ACF}$ & $100.0 \mathrm{ACF}$ & $S$ \\
\hline I117-124 & $50.1 \mathrm{ACF}$ & $70.0 \mathrm{ACF}$ & $70.0 \mathrm{ACF}$ & $45.2 \mathrm{ACF}$ & $70.0 \mathrm{ACF}$ & $93.3 \mathrm{ACF}$ & $\mathrm{S}$ \\
\hline I120-96 & $43.8 \mathrm{ACF}$ & $84.4 \mathrm{ACF}$ & $90.0 \mathrm{ACF}$ & $47.0 \mathrm{ACF}$ & $60.0 \mathrm{ACF}$ & $91.4 \mathrm{ACF}$ & $\mathrm{S}$ \\
\hline I111-69 & $48.1 \mathrm{ACF}$ & $68.1 \mathrm{ACF}$ & $100.0 \mathrm{ACF}$ & $40.0 \mathrm{ACF}$ & $50.0 \mathrm{ACF}$ & 86.2 ACF & $\mathrm{S}$ \\
\hline $\mathrm{I} 105-35$ & $34.1 \mathrm{ACF}$ & $70.0 \mathrm{ACF}$ & $70.0 \mathrm{ACF}$ & 60.9 & $70.0 \mathrm{ACF}$ & $82.5 \mathrm{ACF}$ & S \\
\hline I110-17 & $38.8 \mathrm{ACF}$ & $80.6 \mathrm{ACF}$ & $90.0 \mathrm{ACF}$ & $54.5 \mathrm{AF}$ & $50.0 \mathrm{ACF}$ & 81.7 ACF & S \\
\hline I118-7 & $31.9 \mathrm{ACF}$ & $60.6 \mathrm{ACF}$ & $70.0 \mathrm{ACF}$ & $47.9 \mathrm{ACF}$ & 30.0 & $63.5 \mathrm{ACF}$ & $\mathrm{S}$ \\
\hline I110-54 & $31.0 \mathrm{ACF}$ & 29.9 & 44.4 & 47.1 ACF & $22.2 \mathrm{P}$ & $48.5 \mathrm{ACF}$ & $\mathrm{S}$ \\
\hline I117-121 & $24.3 \mathrm{ACF}$ & $38.1 \mathrm{ACF}$ & $70.0 \mathrm{ACF}$ & $52.1 \mathrm{ACF}$ & $20.0 \mathrm{P}$ & 47.7 ACF & $\mathrm{S}$ \\
\hline I123-73 & $17.7 \mathrm{P}$ & 25.0 & $50.0 \mathrm{~A}$ & $63.9 \mathrm{P}$ & $10.0 \mathrm{P}$ & $32.1 \mathrm{P}$ & $\mathrm{R}$ \\
\hline I117-118 & $10.7 \mathrm{P}$ & $7.5 \mathrm{P}$ & 30.0 & $72.4 \mathrm{P}$ & $0.0 \mathrm{P}$ & $15.6 \mathrm{P}$ & $\mathrm{R}$ \\
\hline I120-92 & $3.4 \mathrm{P}$ & $17.5 \mathrm{P}$ & 30.0 & $93.6 \mathrm{P}$ & $0.0 \mathrm{P}$ & $10.6 \mathrm{P}$ & $\mathrm{R}$ \\
\hline 'Changlot Real' & $4.0 \mathrm{P}$ & $3.8 \mathrm{P}$ & $20.0 \mathrm{P}$ & $83.3 \mathrm{P}$ & $0.0 \mathrm{P}$ & $8.2 \mathrm{P}$ & $\mathrm{R}$ \\
\hline I111-2 & $3.6 \mathrm{P}$ & $8.1 \mathrm{P}$ & $20.0 \mathrm{P}$ & $89.1 \mathrm{P}$ & $0.0 \mathrm{P}$ & $8.1 \mathrm{P}$ & $\mathrm{R}$ \\
\hline 'Frantoio' & $4.6 \mathrm{P}$ & $5.6 \mathrm{P}$ & $11.1 \mathrm{P}$ & $89.2 \mathrm{P}$ & $0.0 \mathrm{P}$ & $7.0 \mathrm{P}$ & $\mathrm{R}$ \\
\hline I113-46 & $2.6 \mathrm{P}$ & $8.8 \mathrm{P}$ & $20.0 \mathrm{P}$ & $93.0 \mathrm{P}$ & $0.0 \mathrm{P}$ & $6.9 \mathrm{P}$ & $\mathrm{R}$ \\
\hline I117-6 & $5.2 \mathrm{P}$ & $0.0 \mathrm{P}$ & $0.0 \mathrm{P}$ & $84.8 \mathrm{P}$ & $0.0 \mathrm{P}$ & $5.8 \mathrm{P}$ & $\mathrm{R}$ \\
\hline 'Arbequina' & $2.7 \mathrm{P}$ & $0.0 \mathrm{P}$ & $0.0 \mathrm{P}$ & $87.0 \mathrm{P}$ & $0.0 \mathrm{P}$ & $4.2 \mathrm{P}$ & $\mathrm{R}$ \\
\hline I117-117 & $3.3 \mathrm{P}$ & $0.0 \mathrm{P}$ & $0.0 \mathrm{P}$ & $92.4 \mathrm{P}$ & $0.0 \mathrm{P}$ & $3.2 \mathrm{P}$ & $\mathrm{R}$ \\
\hline I113-11 & $0.2 \mathrm{P}$ & $0.0 \mathrm{P}$ & $0.0 \mathrm{P}$ & $95.6 \mathrm{P}$ & $0.0 \mathrm{P}$ & $1.1 \mathrm{P}$ & $\mathrm{R}$ \\
\hline I117-120 & $0.0 \mathrm{P}$ & $0.0 \mathrm{P}$ & $0.0 \mathrm{P}$ & $100.0 \mathrm{P}$ & $0.0 \mathrm{P}$ & $0.0 \mathrm{P}$ & $\mathrm{R}$ \\
\hline
\end{tabular}

a Disease parameters: relative area under disease progress curve (RAUDPC); final disease intensity index (FDII); final disease incidence (FDI); relative diseasefree period (RDFP); final dead plant incidence (FDPI); and relative susceptibility index (RSI). Letters beside the disease parameters' values indicate significant differences from reference cultivars according to Dunn's pairwise multiple comparison test at $P \leq 0.05$ : $\mathrm{P}$, 'Picual'; A, 'Arbequina'; C, 'Changlot Real'; and F, 'Frantoio'.

b Resistance category based on the RSI value. Resistant (R) were significantly different from 'Picual' and susceptible (S) were significantly different from 'Frantoio'. 
The effect of verticillium wilt on olive tree development was also observed for earliness of bearing. Notable differences in the proportion of fruiting trees were registered according to the inoculation treatment (noninfested or infested) and resistance category of the genotypes (resistant or susceptible) during both harvest seasons (Fig. 7). During the first harvest season (21 MAP), early-bearing genotypes were mainly observed among resistant genotypes. 'Frantoio', despite its resistant response, had a long unproductive period, similar to I106-48 and I105-35 susceptible breeding selections. On the contrary, I1 17-6 had a shorter unproductive period and higher productive potential, reaching the maximum number of fruiting trees during both years. Remarkable earliness of bearing results were also observed for I1 11-2, which showed a high percentage of fruiting trees regardless of the treatment and symptomatology stage.

\section{Discussion}

Testing breeding selections in $V$. dahliae microplots allowed the evaluation of tree growth and development of VWO epidemics in natural environment conditions in soil infested with one single pathotype. The defoliating pathotype of $V$. dahliae caused symptoms such as defoliation of green leaves peaking from late fall through late spring, such as that occurring in natural infested soils (Jiménez-Díaz et al. 2011; Navas-Cortés et al. 2008). In the semi-controlled conditions, external disease symptoms started at 3 MAP, but it could be detected 7 days after inoculation by the root-dip method in a grow chamber under favorable conditions (Arias-Calderón et al. 2015a). Soil inoculum could require a longer time to establish in the soil and reach the roots. These results suggest that earliness of symptoms development depend on the inoculation methods, as previously found when comparing evaluation procedures under controlled conditions in the grow chamber, and affected other disease parameters such as FDI or FDII (Jiménez-Fernández et al. 2016; LópezEscudero et al. 2007). The same results were observed when comparing different inoculation methods under controlled conditions in the greenhouse (Cirulli et al. 2008). Different disease responses were also observed for the Picual cultivar when comparing root-dip and soil inoculation with cornmeal-sand medium (Varo et al. 2016a).

The DI and DII showed a general tendency to increase during the disease evaluation period; however, decreasing values for these disease variables were also observed in some genotypes at certain time points. This might be attributable to both symptom remission and the recovery of some trees, as previously observed for long-term assays (Santos-Rufo et al. 2017). This behavior is usual for olive trees in naturally infested olive orchards (Navas-Cortés et al. 2008; Trapero et al. 2013a), where symptoms have been observed from May to August (Bubici and Cirulli 2014), similar to our microplot observations. Natural symptom recovery has been associated with resistant olive cultivars (López-Escudero and Blanco-López 2005), which is in line with the results we found for our microplots, where genotypes such as I117-6, I117-117, I113-11, 'Arbequina', 'Frantoio', and 'Changlot Real', categorized as resistant, showed higher symptoms recovery rates. In this sense, tree recovery could be considered a resistant mechanism consisting of the ability to restrict the fungus invasion, which has also been associated with structural and compositional differences in vascular tissues (Keykhasaber et al. 2018). Lower DSI values and higher symptom recovery rates observed in resistant genotypes could support the hypothesis that resistant trees have the capacity to activate mechanisms for the compartmentalization of infected xylem vessels after fungal infection (Keykhasaber et al. 2018).

Symptom remission could be promoted by environmental conditions adverse to fungal development, with high air temperatures during summer causing the declines in DI and DII observed from 14 to 18 MAP in microplots. This effect is characteristic of VWO epidemics (López-Escudero et al. 2007; Navas-Cortés et al. 2008). Similarly, soil temperatures could determine the degree of VWO development among genotypes. In this sense, different optimum temperatures were estimated to induce $V$. dahliae infection depending on the olive cultivar, which could range from 16 to $24^{\circ} \mathrm{C}$ in Picual and Arbequina for the defoliating pathotype, whereas temperatures up to $32^{\circ} \mathrm{C}$ reduced disease progression in both cultivars (Calderón et al.

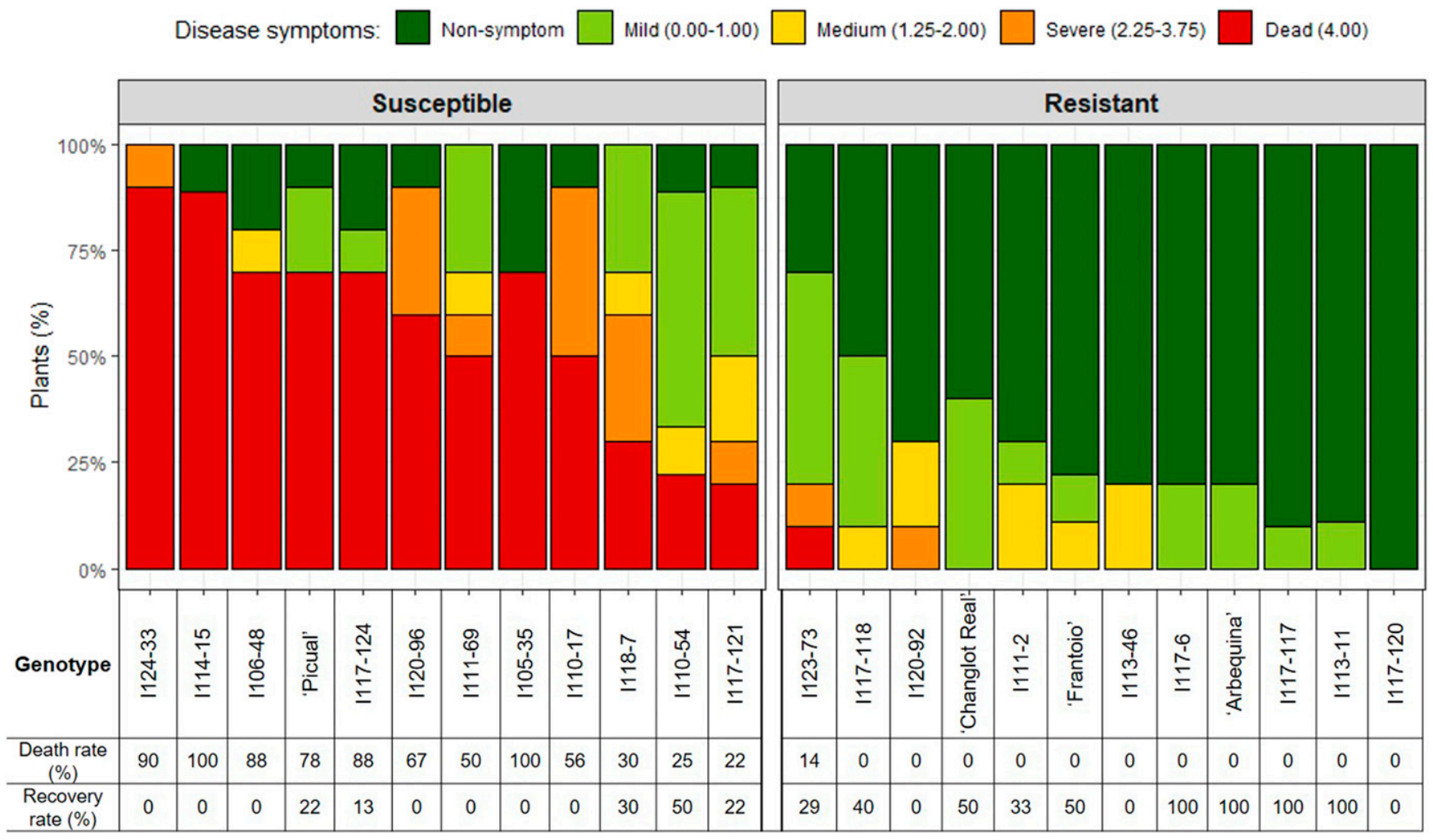

Fig. 4. Frequency of trees with different classes of severity symptoms and death and symptom recovery rates of the 24 genotypes evaluated. Disease symptom severity was classified according to a scale of 0 to 4 for five classes as follows: without symptoms or mild symptoms ( 0 to 1 , including recovered trees); moderate symptoms (1.25 to $2.00)$; severe symptoms (2.25 to 3.75$)$; and dead trees (4). Death and recovery rates were calculated as a percentage of the total number of symptomatic trees. 
2014). During our work, average daily air and soil temperatures ranged from 4.3 to $25.8^{\circ} \mathrm{C}$ and 6.4 to $28.4^{\circ} \mathrm{C}$, respectively, between December 2016 and May 2017 (9 to 14 MAP), concomitant with increased DI and DII values (i.e., in the susceptible 'Picual'). Furthermore, average soil temperatures higher than $30^{\circ} \mathrm{C}$, remission of the DI and symptom severity, and a significant decrease in the inoculum density were observed from June to September (14 to 18 MAP).
During the adverse conditions for VWO development described from June to September, olive trees continued growing and produced new shoots. This new growth remained healthy for fully recovered trees, such as 'Arbequina' and I111-2, or showed symptoms again when the environmental conditions became favorable for the progression of disease, as observed for I123-73. The reasons for this VWO relapse are not fully understood (Bubici and Cirulli 2014;
A

RAUDPC

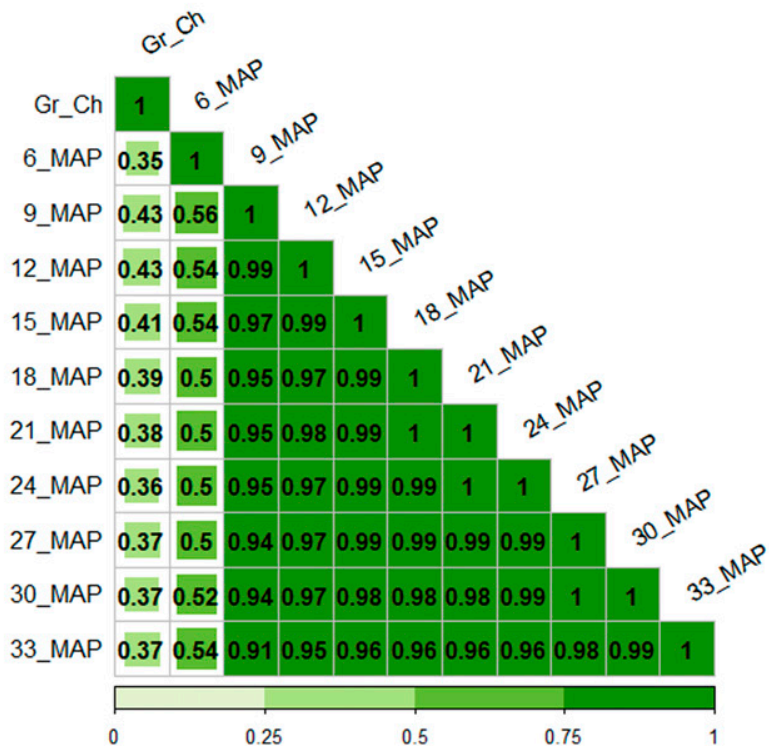

B

RSI

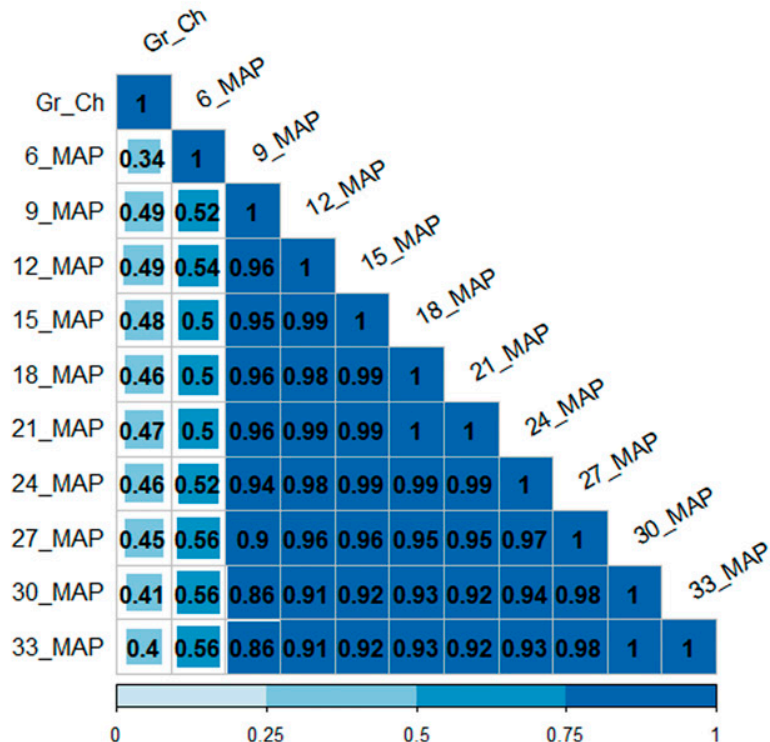

Fig. 5. Spearman correlation analysis of the average relative area under disease progress curve (RAUDPC) and relative susceptibility index (RSI) values for each genotype found by previous evaluations performed in growth chambers (Arias-Calderón et al. 2015a, b) and in microplots from 6 to 33 MAP. A, The RAUDPC. B, The RSI. Gr_Ch, growth chamber results. Results of the microplots at different months after planting (MAP) are shown.

Treatment: Non-infested Infested-Symptomless Infested-Symptomatic
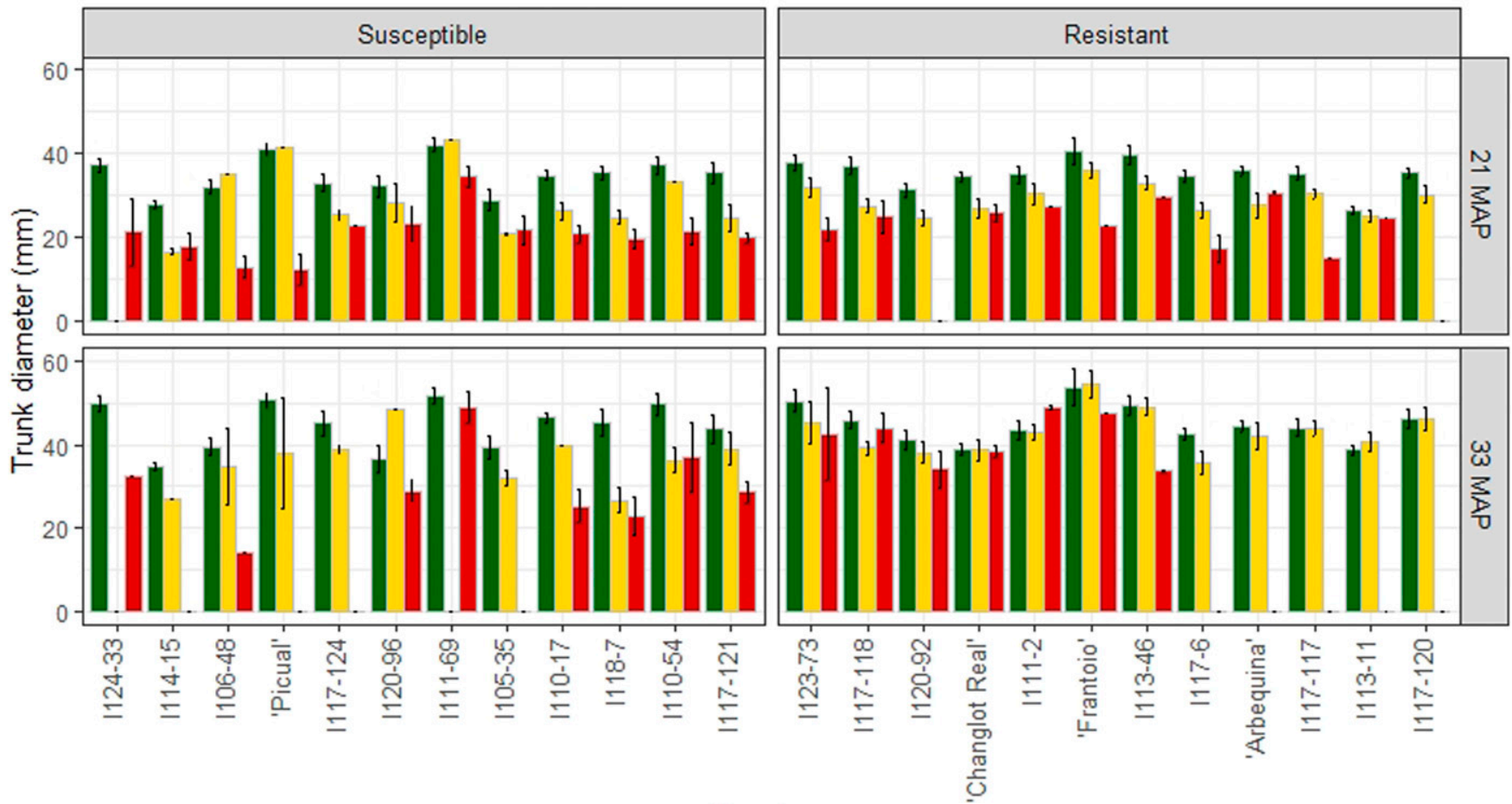

Genotype

Fig. 6. Trunk diameters of noninfested control trees and trees in infested treatment plots (symptomless and symptomatic trees) according to the resistance category and genotype. 
López-Escudero and Blanco-López 2005; López-Escudero and Mercado-Blanco 2011). It could be attributable to fungus remaining viable inside the tree plant or new root infections produced by soil inoculum remaining viable over the whole assessment period. It should be noted that even though soil inoculum experienced the adverse consequences of high temperatures and registered a sharp decline after summer (at 7 and 19 MAP), as in other studies with similar types of inoculum (Gómez-Gálvez et al. 2020; Santos-Rufo et al. 2017), the remaining propagules were enough to cause an epidemic or reinfect the roots (López-Escudero and Blanco-López 2007). In some cases, light increases or variability in inoculum densities were registered for specific microplots, which could be also attributable to the measuring technique or the presence of fungus aggregates in the soil samples, as observed in another study of microplots (López-Escudero and Blanco-López 2007). Despite the different inoculum densities measured among microplots, there were no differences in disease incidence values among experimental blocks. Therefore, similar inoculum densities could be found in soils of commercial olive orchard (Habib et al. 2017; Roca et al. 2016), but the disease incidence has not been directly related to the microsclerotia density in soils (López-Escudero and Blanco-López 2007; Roca et al. 2016; Santos-Rufo et al. 2017).

According to the RSI classification method, only two resistance categories resulted after assessment during a microplot trial instead of the three categories (susceptible, moderately susceptible, and resistant) previously described for tests performed in a growth chamber (Arias-Calderón et al. 2015a, b). Differences in DI and symptom severity for the susceptible control 'Picual' used for RSI standardization were found between these works. This was probably caused by different experimental conditions of the inoculum and/or the environment. In this work, the susceptible response of 'Picual' was consistent with that found by previous evaluations, and Frantoio and Changlot Real responded as resistant cultivars (Arias-Calderón et al. 2015a, b; López-Escudero et al. 2004; Martos-Moreno et al.
2006; Trapero et al. 2013a). The response of 'Arbequina' has been described as very variable, from extremely susceptible by root-dip in the growth chamber (López-Escudero et al. 2004; MartosMoreno et al. 2006) to moderately susceptible in the greenhouse (Trapero et al. 2015), or even resistant in fields (Trapero et al. 2013a) and microplots. These differences could be explained by divergence in the experiments or by symptom recovery typical of longterm experiments.

Eleven of the 20 tested genotypes reached a DI more than $70 \%$ and were characterized as susceptible; this was observed in olive cultivars evaluated in naturally infested soils with a high inoculum density (Trapero et al. 2013a). Because all of the genotypes evaluated during this work were previously selected as potentially resistant when inoculated by root-dip and evaluated in a growth chamber, the results are contrasting (Arias-Calderón et al. 2015a, b). Therefore, the results of microplots with infested soil indicated very low correlation with the those of previous evaluations performed under growth chamber conditions, despite the fact that the same defoliating isolate of $V$. dahliae was used (Arias-Calderón et al. 2015a, b). The different categories assigned to the genotypes could be due to experimental scapements in the previous inoculation by the rootdip method or because of the nonlimited root growth in microplots, which could increase the probability of contact between the roots and $V$. dahliae propagules (Navas-Cortés et al. 2008). Disease response could be affected also in different ways for using different fungal structures as inoculum (conidia or microsclerotia) (Gómez-Gálvez et al. 2019) or different media for fungal culture in the laboratory (Varo et al. 2016a, b).

Despite the differences found between the two testing methods, root-dip is considered an effective first screening test during early stages of the breeding program because it provides results within a shorter time and requires less space (Arias-Calderón et al. 2015a, b; Trapero et al. 2013b). Soil inoculation could be useful for a long-term re-evaluation (Cirulli et al. 2008) during which the

\section{Treatment: $\square$ Non-infested Infested-Symptomless $\square$ Infested-Symptomatic}

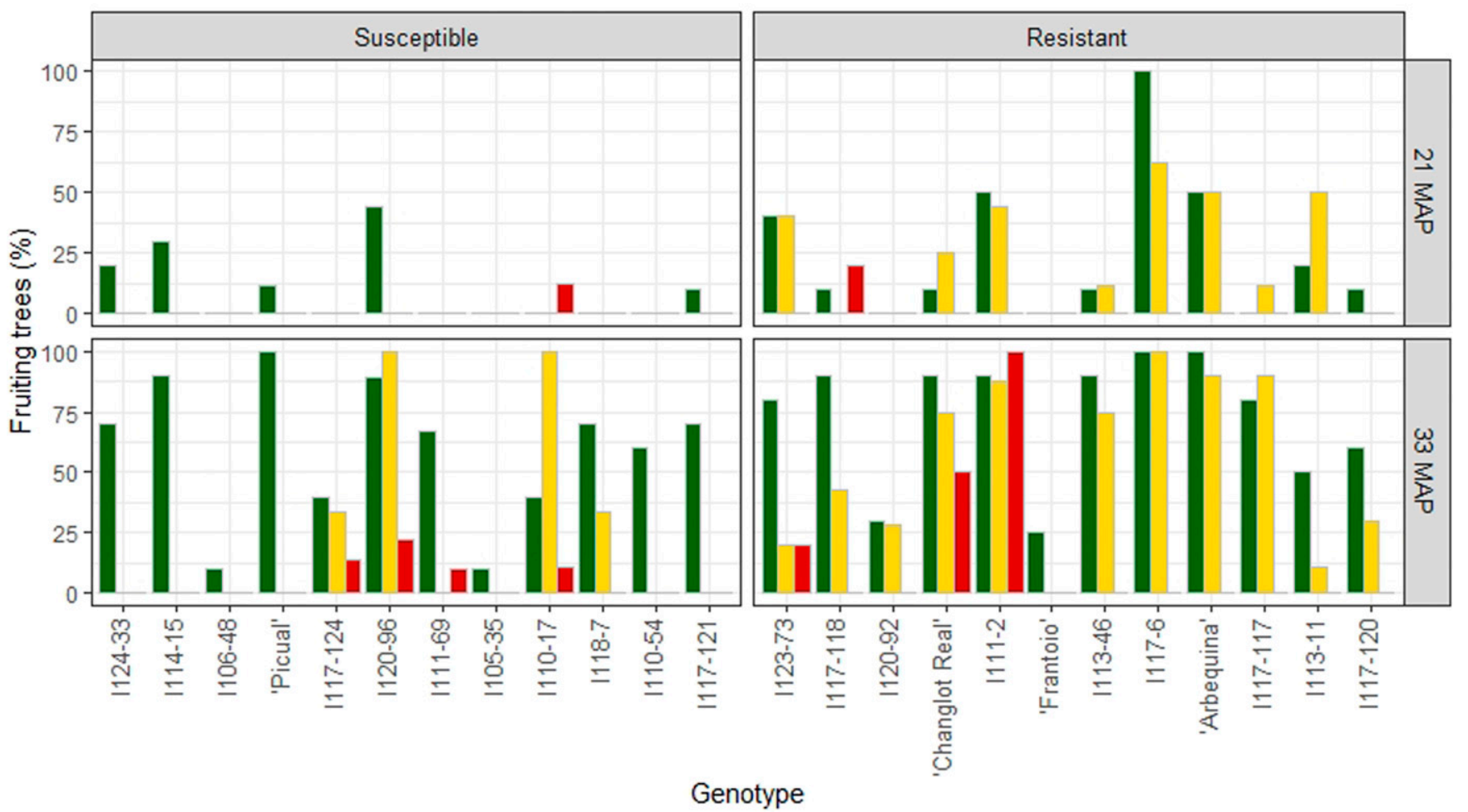

Fig. 7. Percentage of noninfested control fruiting trees and fruiting trees in infested treatment plots (symptomless and symptomatic trees) according to the resistance category and genotype. 
reaction to VWO could be studied during the first months after field planting, when the disease impact is more damaging (Jiménez-Díaz et al. 2011; Trapero et al. 2013b). Results of this work support the possibility of shortening the assessment period under infested microplot conditions to only approximately 12 to 15 MAP. The results obtained for the RAUDPC and RSI values showed a strong correlation from that point of the experiment; therefore, similar classifications of genotypes were obtained since then.

The trial results revealed important differences in tree growth and earliness of bearing. Several reports showed a reduction in the vegetative growth of olive after artificial inoculations with $V$. dahlia and described the delay or cessation of stem growth as a typical symptom of VWO (Martos-Moreno et al. 2006), even in symptomless trees (García-Ruiz et al. 2015). The inhibition of olive growth caused by infection with the defoliating pathotype of $V$. dahliae has been analyzed using the fresh and dry weights of olive trees (Birem et al. 2016; Gómez-Gálvez et al. 2020; Sanei and Razavi 2017; SantosRufo et al. 2018). Shoot length, stem diameter, numbers of leaves per tree, average leaf area, canopy volume, and relative belowground biomass were significantly reduced by $17 \%$ to $38.5 \%$ in 'Picual' grown in infested soil by the defoliating pathotype under natural environmental conditions (Gómez-Gálvez et al. 2020; Santos-Rufo et al. 2018). Differential behaviors associated with the reduction of root and canopy growth among olive cultivars were described (Sanei and Razavi 2017). In this work, olive tree growth in microplots was evaluated using trunk diameter measurements, which are considered highly representative of the total tree vigor (León et al. 2007). Olive trees in infested plots had smaller trunk diameters than noninfested ones, and they were even smaller for symptomatic trees of both susceptible and resistant genotypes. Among the studied cultivars, Frantoio had the highest trunk diameter values, thus confirming the high vigor of this cultivar (León et al. 2007).

A negative effect of the disease on earliness of bearing was also observed, particularly for susceptible genotypes. Therefore, the cultivation of susceptible genotypes could imply a substantial decrease in fruit production, even when the plants are asymptomatic, because of longer unproductive periods and higher disease severity, in contrast to resistant genotypes. This loss of productivity caused by VWO has been previously described for many olive cultivars worldwide (Jiménez-Díaz et al. 2011). For 'Picual', the infection caused by the defoliating pathotype reduced the number of fruits per tree by $88.7 \%$ in a study involving infested soil (Gómez-Gálvez et al. 2020). Among resistant cultivars, Frantoio was confirmed to have the longest unproductive period compared with Arbequina and Picual, as previously reported (León et al. 2007). Among the breeding selections, some resistant genotypes, such as I111-2 and I117-6, had shorter unproductive periods and a high percentage of fruiting trees, even under inoculation conditions, thus representing an agronomic trait of paramount importance.

The usefulness of the evaluation of breeding selections for VWO resistance by artificial infested soils with propagules of $V$. dahliae defoliating pathotype was demonstrated under natural environmental conditions. Disease and tree growth had progression similar to that in commercial olive orchards. This evaluation process resulted in more restrictions when identifying resistant genotypes than did a previous evaluation performed in a growth chamber. The lack of correlations among disease parameters found during disease assessment under controlled and natural environment conditions revealed the important role of the environment in the olive genotype- $V$. dahliae interaction. Future studies are necessary to determine the effects of environmental conditions on the resistance stability in olive across different environmental conditions. Comprehensive agronomic characterization of the resistant promising selections for characteristics, such as oil content, quality, and suitability for different olivegrowing systems, are also necessary before they can be released as new cultivars.

\section{Acknowledgments}

This research was financially supported by IFAPA project AVA2019.027 and partially funded by European Regional Development Fund (ERDF). Alicia Serrano is grateful for the funding received from the Researcher Training Program of INIAAutonomous Communities Research Centers (FPI-INIA).

\section{Literature Cited}

Arias-Calderón, R., León, L., Bejarano-Alcázar, J., Belaj, A., de la Rosa, R., and Rodríguez-Jurado, D. 2015a. Resistance to Verticillium wilt in olive progenies from open-pollination. Sci. Hortic. (Amsterdam) 185:34-42.

Arias-Calderón, R., Rodríguez-Jurado, D., Bejarano-Alcázar, J., Belaj, A., de la Rosa, R., and León, L. 2015b. Evaluation of Verticillium wilt resistance in selections from olive breeding crosses. Euphytica 206:619-629.

Arias-Calderón, R., Rouiss, H., Rodríguez-Jurado, D., de la Rosa, R., and León, L. 2014. Variability and heritability of fruit characters in olive progenies from open-pollination. Sci. Hortic. (Amsterdam) 169:94-98.

Birem, F., Alcántara-Vara, E., and López-Escudero, F. J. 2016. Water consumption and vegetative growth progress in resistant and susceptible olive cultivars infected by Verticillium dahliae. AS. 07:230-238.

Bubici, G., and Cirulli, M. 2014. Natural recovery from Verticillium wilt in olive: can it be exploited in a control strategy? Plant Soil 381:85-94.

Butterfield, E. J., and DeVay, J. E. 1977. Reassessment of soil assays for Verticillium dahliae. Phytopathology 67:1073-1078.

Calderón, R., Lucena, C., Trapero-Casas, J. L., Zarco-Tejada, P. J., and NavasCortés, J. A. 2014. Soil temperature determines the reaction of olive cultivars to Verticillium dahliae pathotypes. PLoS One 9:e110664.

Cirulli, M., Colella, C., D'Amico, M., Amenduni, M., and Bubici, G. 2008. Comparison of screening methods for the evaluation of olive resistance to Verticillium dahliae Kleb. J. Plant Pathol. 90:7-14.

Fernández-Escobar, R., de la Rosa, R., León, L., Gómez, J. A., Testi, F., Orgaz, M., Gil-Ribes, J. A., Quesada-Moraga, E., Trapero, A., and Msallem, M. 2013. Evolution and sustainability of the olive production systems. Pages 11-42 in: Present and future of the Mediterranean olive sector. N. Arcas, F.N. Arroyo López, J. Caballero, R. D’Andria, M. Fernández, R. Fernández-Escobar, A. Garrido, J. López-Miranda, M. Msallem, M. Parras, L. Rallo, and R. Zanoli, eds. Options Méditerranéennes: Série A. Séminaires Méditerranéens; n. 106. CIHEAM/IOC, Zaragoza, Spain.

García-Ruiz, G. M., Trapero, C., Del Rio, C., and López-Escudero, F. J. 2014. Evaluation of resistance of Spanish olive cultivars to Verticillium dahliae in inoculations conducted in greenhouse. Phytoparasitica 42:205-212.

García-Ruiz, G. M., Trapero, C., Varo-Suárez, Á., Trapero, A., and LópezEscudero, F. J. 2015. Identifying resistance to Verticillium wilt in local Spanish olive cultivars. Phytopathol. Mediterr. 54:453-460.

Gómez-Gálvez, F. J., Hidalgo-Moya, J. C., Vega-Macías, V., Hidalgo-Moya, J. J., and Rodríguez-Jurado, D. 2019. Reduced introduction of Verticillium dahliae through irrigation systems and accumulation in soil by injection of peroxygen-based disinfectants. Plant Pathol. 68:116-126.

Gómez-Gálvez, F. J., Vega-Macías, V., Hidalgo-Moya, J. C., Hidalgo-Moya, J. J., and Rodríguez-Jurado, D. 2020. Application to soil of disinfectants through irrigation reduces Verticillium dahliae in the soil and verticillium wilt of olive. Plant Pathol. 69:272-283.

Goud, J.-K. C., Termorshuizen, A. J., and van Bruggen, A. H. C. 2011. Verticillium wilt in nursery trees: damage thresholds, spatial and temporal aspects. Eur. J. Plant Pathol. 131:451-465.

Habib, W., Choueiri, E., Baroudy, F., Tabet, D., Gerges, E., Saab, C., et al. 2017. Soil inoculum density of Verticillium dahliae and Verticillium wilt of olive in Lebanon. Ann. Appl. Biol. 170:150-159.

Huisman, O. C., and Ashworth, L. J. 1974. Quantitative assessment of Verticillium albo-atrum in field soils: procedural and substrate improvements. Phytopathology 64:1043-1044.

Jiménez-Díaz, R. M., Cirulli, M., Bubici, G., del Mar Jiménez-Gasco, M., Antoniou, P. P., and Tjamos, E. C. 2011. Verticillium wilt, a major threat to olive production: current status and future prospects for its management. Plant Dis. 96:304-329.

Jiménez-Fernández, D., Trapero-Casas, J. L., Landa, B. B., Navas-Cortés, J. A., Bubici, G., Cirulli, M., et al. 2016. Characterization of resistance against the olive-defoliating Verticillium dahliae pathotype in selected clones of wild olive. Plant Pathol. 65:1279-1291.

Keykhasaber, M., Thomma, B. P. H. J., and Hiemstra, J. A. 2018. Verticillium wilt caused by Verticillium dahliae in woody plants with emphasis on olive and shade trees. Eur. J. Plant Pathol. 150:21-37.

Landa, B. B., Pérez, A. G., Luaces, P., Montes-Borrego, M., Navas-Cortés, J. A., and Sanz, C. 2019. Insights into the effect of Verticillium dahliae defoliatingpathotype infection on the content of phenolic and volatile compounds related to the sensory properties of virgin olive oil. Front. Plant Sci. 10:232.

León, L., de la Rosa, R., Barranco, D., and Rallo, L. 2007. Breeding for early bearing in olive. HortScience 42:499-502.

Levin, A. G., Lavee, S., and Tsror (Lahkim), L. 2003. Epidemiology of Verticillium dahliae on olive (cv. Picual) and its effect on yield under saline conditions. Plant Pathol. 52:212-218.

López-Escudero, F. J., and Blanco-López, M. A. 2005. Recovery of young olive trees from Verticillium dahliae. Eur. J. Plant Pathol. 113:367-375.

López-Escudero, F. J., and Blanco-López, M. A. 2007. Relationship between the inoculum density of Verticillium dahliae and the progress of Verticillium wilt of Olive. Plant Dis. 91:1372-1378. 
López-Escudero, F. J., Blanco-López, M. Á., Rincón, C. D. R., and Reig, J. M. C. 2007. Response of olive cultivars to stem puncture inoculation with a defoliating pathotype of Verticillium dahliae. HortScience 42:294-298.

López-Escudero, F. J., and Mercado-Blanco, J. 2011. Verticillium wilt of olive: a case study to implement an integrated strategy to control a soil-borne pathogen. Plant Soil 344:1-50.

López-Escudero, F. J., del Río, C., Caballero, J. M., and Blanco-López, M. A. 2004. Evaluation of olive cultivars for resistance to Verticillium dahliae. Eur. J. Plant Pathol. 110:79-85.

López-Escudero, F. J., Mercado-Blanco, J., Roca, J. M., Valverde-Corredor, A., and Blanco-López, A. M. 2010. Verticillium wilt of olive in the Guadalquivir Valley (Southern Spain): relations with some agronomical factors and spread of Verticillium dahliae.Phytopathol. Mediterr. 49:370-380.

Martos-Moreno, C., López-Escudero, F. J., and Blanco-López, M. A. 2006. Resistance of olive cultivars to the defoliating pathotype of Verticillium dahliae. HortScience 41:1313-1316.

Montes-Osuna, N., and Mercado-Blanco, J. 2020. Verticillium wilt of olive and its control: What did we learn during the last decade? Plants 9:735.

Navas-Cortés, J. A., Landa, B. B., Mercado-Blanco, J., Trapero-Casas, J. L., Rodríguez-Jurado, D., and Jiménez-Díaz, R. M. 2008. Spatiotemporal analysis of spread of infections by Verticillium dahliae pathotypes within a high tree density olive orchard in southern Spain. Phytopathology 98: 167-180.

Roca, L. F., Moral, J., Trapero, C., Blanco-López, M. Á., and López-Escudero, F. J. 2016. Effect of inoculum density on Verticillium wilt incidence in commercial olive orchards. J. Phytopathol. 164:61-64.

Rodríguez-Jurado, D. 1993. Interacciones huésped-parásito en la marchitez del olivo (Olea europaea L.) inducida por Verticillium dahliae Kleb. PhD Thesis, University of Córdoba, Spain (in Spanish).
Rodríguez-Jurado, D., Moraño-Moreno, R., and Bejarano-Alcázar, J. 2008 Dispersion of defoliating and non-defoliating pathotype of Verticillium dahliae in host crops by irrigation water in southern Spain. Eur. J. Plant Pathol. 90:419-420.

Sanei, S. J., and Razavi, S. E. 2017. Resistance and vegetative growth analysis of some olive cultivars in response to a defoliating pathotype of Verticillium dahliae Kleb. Int. J. Hortic. Sci. Technol. 4:239-250.

Santos-Rufo, A., Hidalgo, J. J., Hidalgo, J. C., Vega, V., and Rodríguez-Jurado, D. 2018. Morphophysiological response of young olive trees to Verticillium wilt under different surface drip irrigation regimes. Plant Pathol. 67:848-859.

Santos-Rufo, A., Vega, V., Hidalgo, J. J., Hidalgo, J. C., and Rodríguez-Jurado, D. 2017. Assessment of the effect of surface drip irrigation on Verticillium dahliae propagules differing in persistence in soil and on verticillium wilt of olive. Plant Pathol. 66:1117-1127.

Trapero, C., Díez, C. M., Rallo, L., Barranco, D., and López-Escudero, F. J. 2013b. Effective inoculation methods to screen for resistance to Verticillium wilt in olive. Sci. Hortic. (Amsterdam) 162:252-259.

Trapero, C., Rallo, L., López-Escudero, F. J., Barranco, D., and Díez, C. M. 2015. Variability and selection of verticillium wilt resistant genotypes in cultivated olive and in the Olea genus. Plant Pathol. 64:890-900.

Trapero, C., Serrano, N., Arquero, O., Del Río, C., Trapero, A., and LópezEscudero, F. J. 2013a. Field resistance to Verticillium wilt in selected olive cultivars grown in two naturally infested soils. Plant Dis. 97:668-674.

Varo, A., Moral, J., Lozano-Tóvar, M. D., and Trapero, A. 2016a. Development and validation of an inoculation method to assess the efficacy of biological treatments against Verticillium wilt in olive trees. BioControl 61:283-292.

Varo, A., Raya-Ortega, M. C., and Trapero, A. 2016b. Enhanced production of microsclerotia in recalcitrant Verticillium dahliae isolates and its use for inoculation of olive plants. J. Appl. Microbiol. 121:473-484. 